\title{
Propuesta de Tutoría Telemática A.D.E.N. (Análisis, Detección y Evaluación de Necesidades) para la Pequeña y Mediana \\ Empresa.
}

\author{
M. Rosa Fernández Sánchez \\ dvirtu6eusal.es \\ Universidad de Salamanca
}

\section{INTRODUCCIÓN}

La globalización de la actividad consecuencia del impacto de las NTIC en el contexto empresarial, la apertura hacia los mercados europeos, los cambios tecnológicos, la fragmentación de la demanda, se sitúan entre las fuerzas de cambio que han impulsado un "nuevo entorno empresarial", caracterizado por nuevos modelos de organización y gestión, y especialmente, por un cambio de perspectiva sobre el factor humano en las empresas. Éstas últimas, marcan sus líneas estratégicas con un enfoque total hacia sus empleados, situándolos como punto clave de competitividad, tal y como en este momento lo es la tecnología.

Se hace vigente con estas transformaciones la progresiva demanda desde los ámbitos empresariales de empleados formados y polivalentes, lo que hace que debamos plantearnos respuestas desde el ámbito educativo, abriendo líneas de actuación que mejoren las prácticas formativas actuales.

La complejidad de tratar un tema de esta índole reside en la confluencia de criterios económicoeducativos, donde se ahonda en aspectos en los que aún existe un cierto arraigo a determinadas actitudes que complejizan la definición de la relación entre ambos ámbitos; relación rodeada de matices de diferentes disciplinas que caracterizan los trabajos situados en el contexto de la Pedagogía Laboral.

La propuesta que hacemos, situándose en ese contexto, plantea una respuesta a las PYMEs, distanciada del mundo de cambios que asola la sociedad y al margen de la formación continua por diferentes motivos, quizás el más importante una falta total de recursos y de tiempo para dedicar a acciones formativos que normalmente son puntuales y resultan demasiado costosas. Encontramos en los medios telemáticos y la red Internet, un buen soporte para responder a estas dificultades y mediar el proceso de transformación de información en conocimientos, de gestión de ese conocimiento y de promoción de nuevos.

\section{PANORAMA FORMATIVO-EMPRESARIAL.}

Si bien encontramos un cambio de perspectiva en torno al recurso humano dentro de las empresas, debemos plantearnos una doble línea reflexiva: una de ella marcada por la necesidad de trabajadores formados, con conocimientos actualizados y destrezas requeridas para el puesto a desempeñar y por otra, la demanda de los propios empleados preocupados por su mejora profesional, su motivación y su participación en la empresa. Hallamos una respuesta acorde a estas dos ideas y capaz de equilibrarlas: la Orientación Profesional Empresarial. Situando una base en esta disciplina, se puede establecer un sistema de tutoría empresarial que forme un lazo de unión entre las necesidades de la propia empresa y las necesidades que demanda el empleado.

Por otro lado, pero a la vez en relación a este tema se hace indispensable el proceso formativo 
empresarial, determinándose como una estrategia más en la consecución de los fines empresariales en el contexto tan variable que se sitúan las empresas. Este proceso, tradicionalmente basado en sistemas exclusivamente presenciales, se ve complementado con la aparición de nuevas metodologías que se apoyan en la evolución de los sistemas de tratamientos de la información. La evolución de estos sistemas se dirige a la optimización de los sistemas de formación, disminuyendo los costes y flexibilizando los tiempos de aprendizaje, a la vez que procuran una mayor adecuación a las necesidades formativas. Justamente esa adaptación es la clave para el desarrollo de acciones formativas eficaces y con impacto a largo plazo. Si la PYME encontraba trabas a los sistemas tradicionales, puede encontrar en éstos la respuesta a sus necesidades formativas por un lado, porque constituyen un ahorro de costes en recursos y por otro, por la flexibilidad que permiten en el propio proceso de formación, adaptándose al ritmo y al tiempo de los usuarios.

\section{RESPUESTA DESDE EL ÁMBITO PEDAGÓGICO: TUTORÍA TELEMÁTICA A.D.E.N.}

Detectado el problema de la PYME en cuanto a la formación, queremos aprovechar la potencialidad de los medios tecnológicos, especialmente de la red Internet, para dar una posible solución a este tipo de empresas: una tutoría telemática de Análisis, Detección y Evaluación de Necesidades (A.D.E.N.) que recoja además del matiz estrictamente formativo, también el de desarrollo profesional, estableciendo recursos tanto para el diagnóstico completo de necesidades de formación como una guía de desarrollo profesional, en la que el tutorizado evaluará su trayectoria hasta el momento y fijará sus objetivos a corto y largo plazo, estableciendo los recursos a su alcance con ayuda del tutor.

\subsection{La Tutoría A.D.E.N. como espacio virtual de colaboración.}

La Tutoría Telemática A.D.E.N. es un diseño cuya finalidad es conocer con mayor profundidad las necesidades de actualización profesional para mejorar la calidad de las acciones de formación continua de la PYME, incorporando una manera innovadora de desarrollarlo basada en las Tecnologías de la Información.

La creación de la Tutoría Telemática A.D.E.N. se ha pensado desde el aprovechamiento de un espacio virtual de colaboración, con una línea de investigación-acción, es decir, indagando sobre la propia práctica que cada día se desarrolla en las empresas. Todo ello mediante las relaciones interpersonales que a través de las de van a motorizar el círculo de herramientas y recursos en base a los cuales las personas que integran esa empresa van a gestionar sus necesidades tanto formativas como de desarrollo profesional.

Desde el punto de vista social del enfoque socio-cultural del aprendizaje, esta tutoría se concibe como una propuesta destinada a la creación de un escenario educativo innovador, ofreciendo una diversidad de oportunidades para la interacción social, la comunicación interpersonal y la práctica en la solución de diversos problemas de influencia más particular. Definimos así, con la Tutoría A.D.E.N. un entorno informal de aprendizaje, donde este se va a adquirir colaborativamente. Uniendo este punto de vista al empresarial, lo que pretendemos es establecer un proceso de diagnóstico de necesidades proponiendo un espacio rico en interacciones, a través de los cuales se va a determinar, por parte del tutor y los participantes esas necesidades formativas. La clave del carácter intersubjetivo, por tanto, está apoyada en unos objetos de atención comunes (que van a ser el diagnóstico de necesidades formativas) y unos recursos compartidos (brindados por esta tutoría). Ofrece, así mismo, una diversificación de movimientos, actividades y puntos de encuentro en la que intervenir e interaccionar. Interacción y participación de los usuarios en el proceso que lleva consigo la Tutoría, refiriéndonos al proceso de diagnostico de necesidades y el plan de desarrollo profesional). Incidimos en que la Tutoría A.D.E.N. no es sólo un medio tecnológico en sí sino que se constituye como un sistema de tutorización en el que confluyen varios elementos: un tutor, unos empleados, una empresa y un contexto que la rodea y en la que se sitúa. 
El espacio está constituido para tres tipos de usuario, permitiendo la opción de dos o tres tipos dependiendo de las características y necesidades de las empresas y participantes destinatarios de la Tutoría. El que llamaremos Usuario 1 se refiere a los empleados de la PYME, el Usuario 2 a los directivos y el Usuario Tutor se corresponde al Tutor que gestiona la tutoría y toda la información que la empresa desee introducir. Ya decimos que la elaboración de estos tres caminos ha sido con la idea de flexibilizar la tutoría de cara a que pueda adaptarse a más de un tipo de PYME (versatilidad en cuanto a entornos de uso - no sabemos con exactitud en qué empresa y situación será aplicada). Cada empresa puede decidir optar sólo por el Usuario 1 y Tutor (si es una mediana empresa por ejemplo), el Usuario 2 y el Tutor (si es solo una tutoría para directivos de PYMEs) o todos (si es por ejemplo una gestoría-asesoría que tutoriza a varias PYMEs).

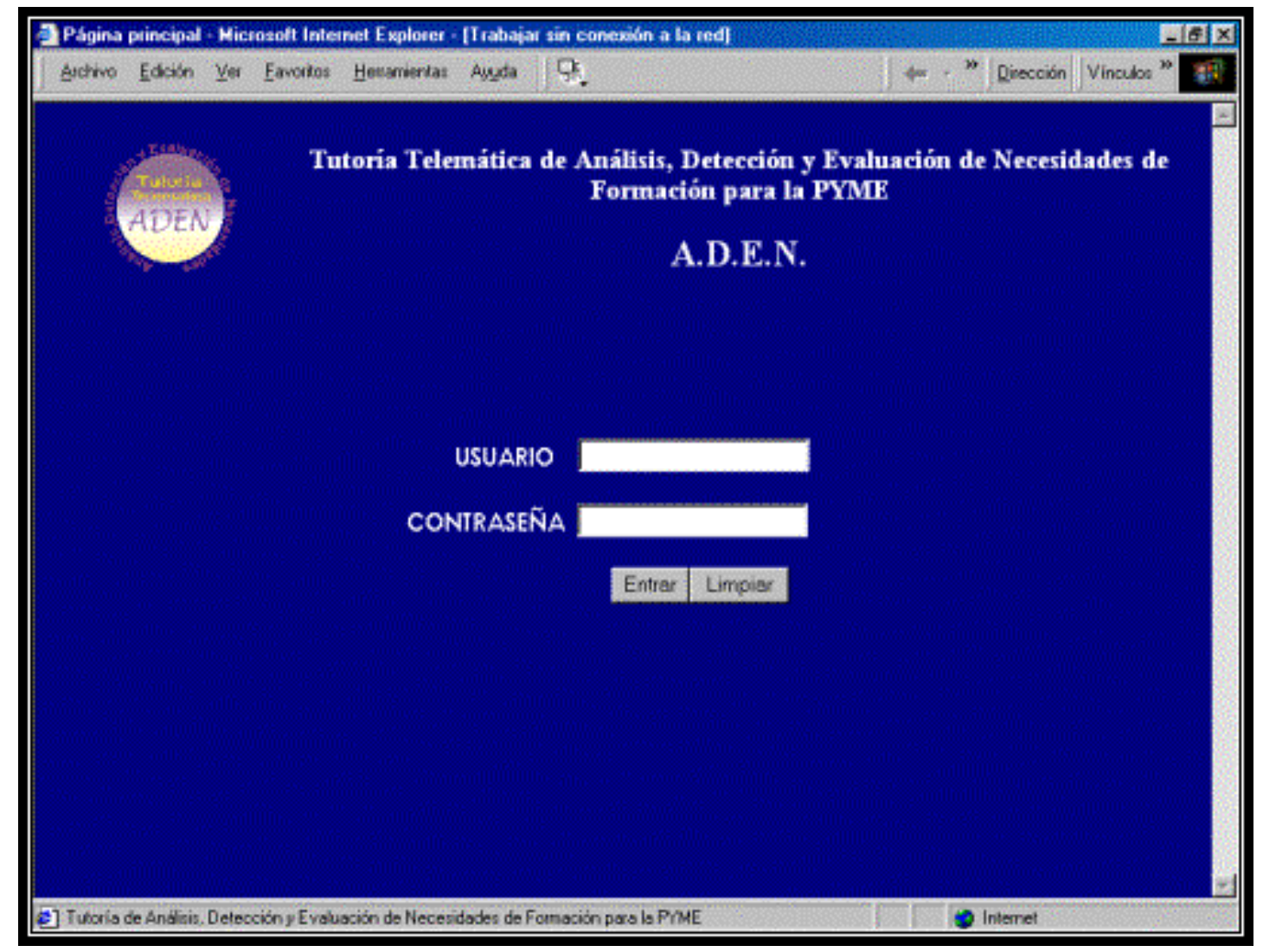

Figura 1: Autorización de entrada a Tutoría A.D.E.N.

Los tres caminos que constituyen la Tutoría A.D.E.N. se han organizado en cinco unidades temáticas básicas de funcionamiento que conforman el índice temático, apareciendo siempre visible como menú de navegación, evitando que el usuario se pierda por las páginas y permitiendo así el máximo aprovechamiento de la sesión de tutoría y la rápida habituación a la navegación. Igualmente, todos los hipervínculos son a no más de 3 niveles por este motivo. Con este fin también se ha creado una de las unidades temáticas: "Ayuda", similar para los tres usuarios, donde además de establecer el mapa de navegación adaptado para cada uno de ellos, da información precisa sobre la filosofía del diseño y los botones principales de navegación.

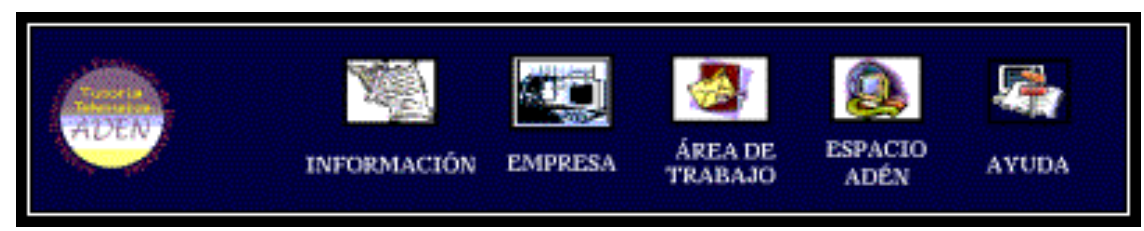

Figura 2: Menú Principal de Navegación de la Tutoría A.D.E.N.

El usuario 1 y 2 poseen una sola diferencia entre ellos y es la constitución en la subunidad Espacio Compartido dentro de la unidad "Espacio A.D.E.N.", un foro exclusivamente para directivos de la empresa o del sector, ofreciendo el matiz especial que los directivos puedan demandar desde su 
posición, abriendo sus opiniones con la posibilidad de generar planes colaborativos y agrupados entre varias PYMEs, tanto en temas formativos como en otros que puedan considerarse oportunos. El usuario Tutor, al ser el gestor de la tutoría será el encargado de modificar y actualizar toda las informaciones, incluyendo en su camino varias subunidades que iremos describiendo a continuación por áreas.

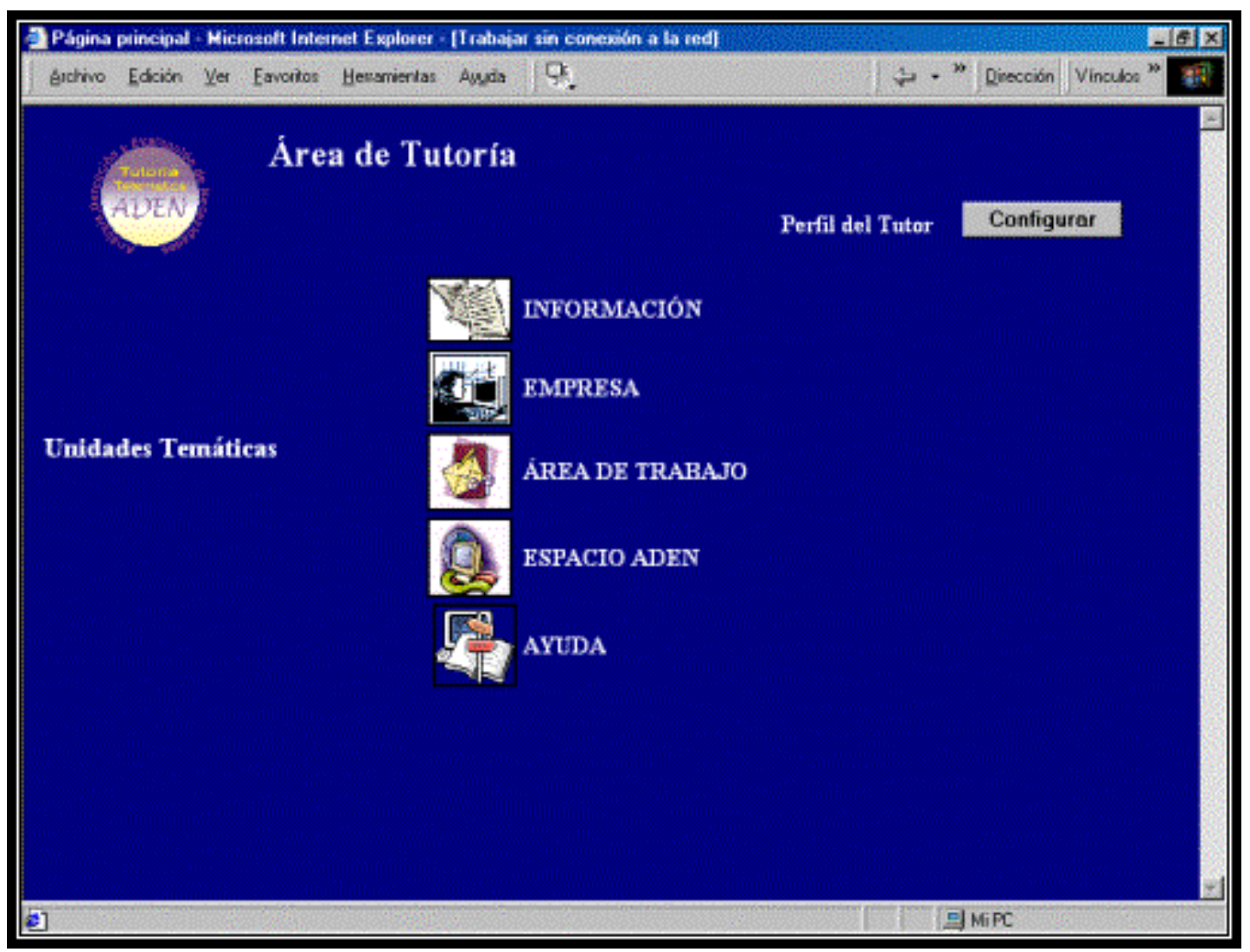

Figura 3: Página principal del Tutor. Área de tutoría.

\section{Área Información:}

Esta unidad ofrece un conjunto de informaciones de diversa índole en relación con el mercado del sector correspondiente, tanto noticias propiamente específicas, hasta enlaces a otras páginas donde se encuentra información útil y un buscador para que posibilite la exploración de aquella información que no se encuentre en la web. Para todo aquello que no encuentre y requiera, incluimos un formulario de petición de información específica que el tutorizado considere importante para su conocimiento. El fin último de esta unidad es que el tutorizado conozca el sector y el tipo de empresa en que trabaja y actualizar sus conocimientos sobre ambos. 


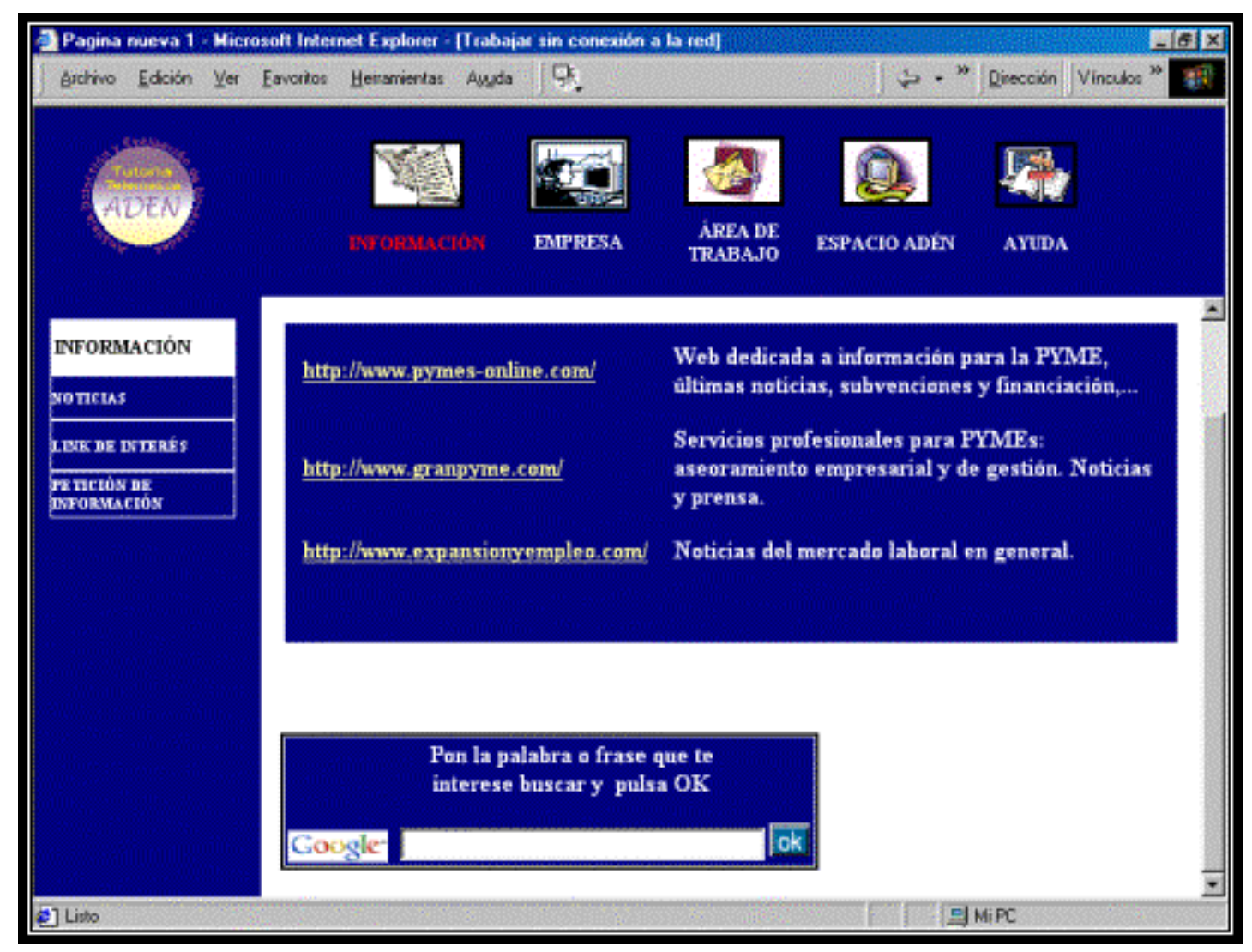

Figura 4: Unidad de Información. Link de Interés.

\section{Área Empresa:}

Empresa ofrece, como parte central, un organigrama de la empresa, con todos los puestos y dependencia directa, si la hubiese. Dos subunidades básicas integran esta unidad:

- Características de la empresa: muestra información específica sobre la labor de la empresa, objetivos y metas, recursos, etc., con el fin de que el usuario tenga una información clara de todo lo que hace su empresa y con qué recursos se cuenta para conseguir las metas propias de la misma.

- Tablón de auncios/eventos: este tablón ofrece anuncios de la empresa a considerar por el tutorizado y eventos de importancia que toman en cuenta la participación del mismo.

Esta unidad pretende hacer partícipe al tutorizado de los eventos y características de la empresa de la que forma parte.

\section{Área de trabajo:}

Esta unidad es un punto de encuentro con los puestos de trabajo de la empresa, de cara al posible interés del tutorizado por establecer su carrera en torno a los mismos. Ofrece:

- Áreas de trabajo en la empresa: en el que se indican todas las áreas de la empresa con sus respectivas funciones, características y perfil del trabajador.

- Oferta formativa: en esta unidad se anuncia la oferta interna o externa que pueda considerar el empleado de cara al establecimiento de su carrera profesional.

- Mi área de trabajo: donde constará el área de trabajo del empleado con sus funciones, tareas y fines. Esta unidad permite conocer al empleado y le permite auto-analizar sus funciones en el área que desempeñe (mi perfil de trabajador), lo que puede ayudarle a conocer qué aspectos debe mejorar de esas funciones requeridas. 


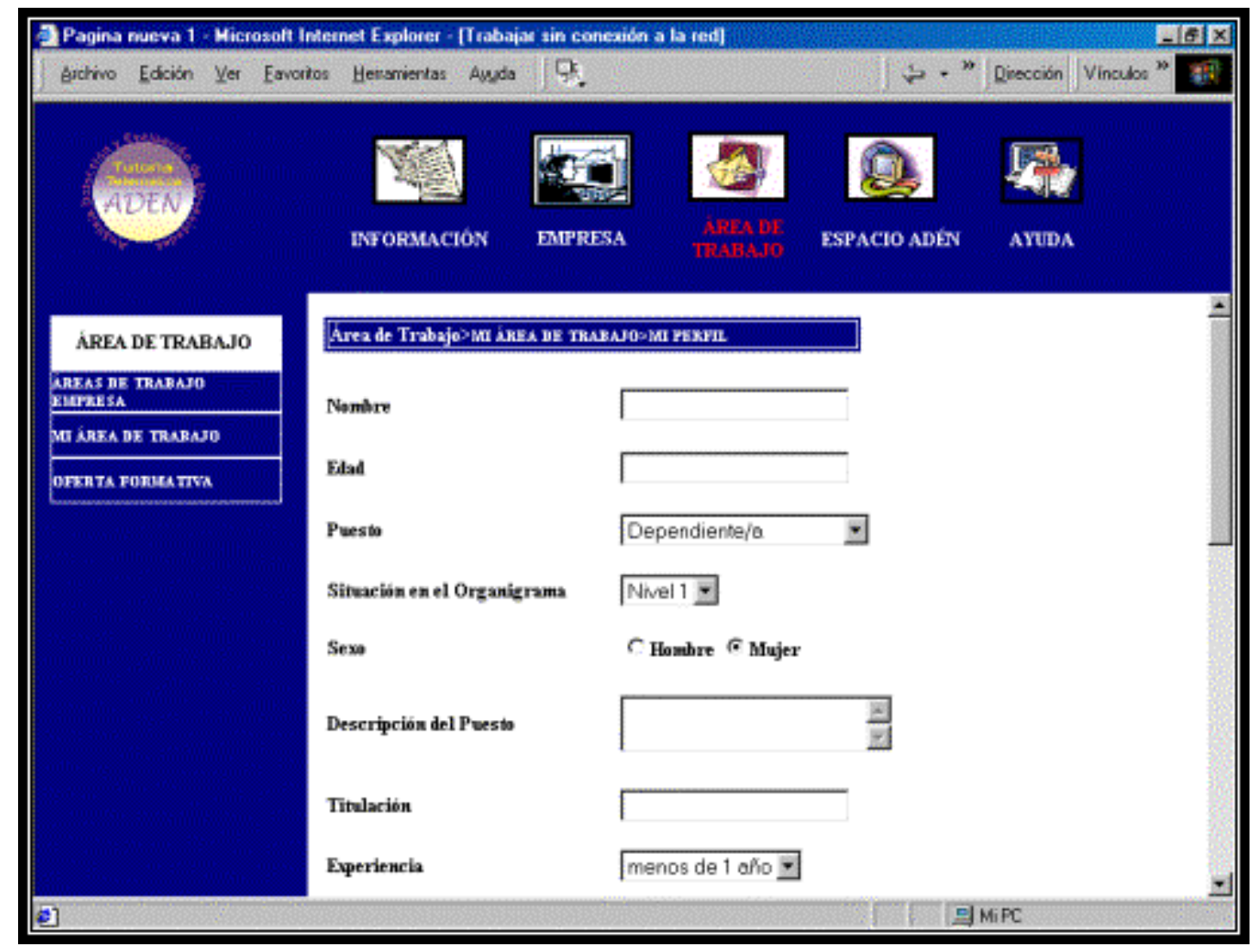

Figura 5: Unidad Área de Trabajo, subunidad Mi área de trabajo. Configuración de Mi Perfil.

En esta unidad el Tutor en lugar de Mi área de trabajo, se encuentra con Análisis de puestos de trabajo, pues será el que deba efectuar, en colaboración con la empresa, el análisis previo del puesto correspondiente.

\section{Área Espacio A.D.E.N:}

Es la unidad quizás más importante de la tutoría puesto que establece la zona individual y el espacio compartido donde se lleva a cabo, más directamente, pues en las áreas anteriores también se puede recabar información, la detección de necesidades de formación. Consta de dos subunidades, divididas a la vez en varias:

- Espacio Individual: forma parte de la zona personal y confidencial del tutorizado. En ella se ofrece la tutoría individual y personalizada, constando de varias partes:

Autoevaluaciones: Unidad que ofrece la posibilidad de generar autocuestionarios de evaluación. Proporciona al usuario un cuestionario de autoevaluación de necesidades.

.Cuestionarios: Esta unidad proporciona cuestionarios de detección de necesidades que el usuario deberá realizar individualmente.

.Correo Electrónico: En esta unidad el usuario tiene su disposición un servicio de correo electrónico, para solicitar consultas, asesoramiento, y para ponerse en contacto con el tutor o compañeros, indicando la prioridad de su consulta..

.Guía de Desarrollo Profesional: Esta guía permite evaluar las metas profesionales con la mediación del Tutor, analizando y evaluando los recursos necesarios para conseguirla. Para elaborarla proponemos recursos gratuitos al servicio de este fin, como el llamado Storm Navigator [1] . Este medio proporciona información al Tutor sobre necesidades y demandas de los tutorizados.

El tutor se encuentra con una subunidad más en el que se ofrecen recursos para la realización del 
análisis y la evaluación de necesidades, ofreciéndole diversas técnicas (Técnicas ADEN), para ello. Es un recurso opcional, puesto que el Tutor debe ser quien determine cómo llevar a cabo el proceso de diagnóstico junto con los Usuarios

- Espacio compartido: Zona, como su nombre indica, de espacio compartido y trabajo en colaboración con la participación de todos los tutorizados. Consta de las siguiente unidades:

. Foro General: Espacio de compartición de ideas, información y conocimientos, guiado por el tutor, que permite la recogida de información y la participación de todos los miembros, el diagnóstico y las posteriores acciones formativas. Es un foro general en el que se podrán marcar los temas a tratar y donde podrán participar todos los tutorizados.

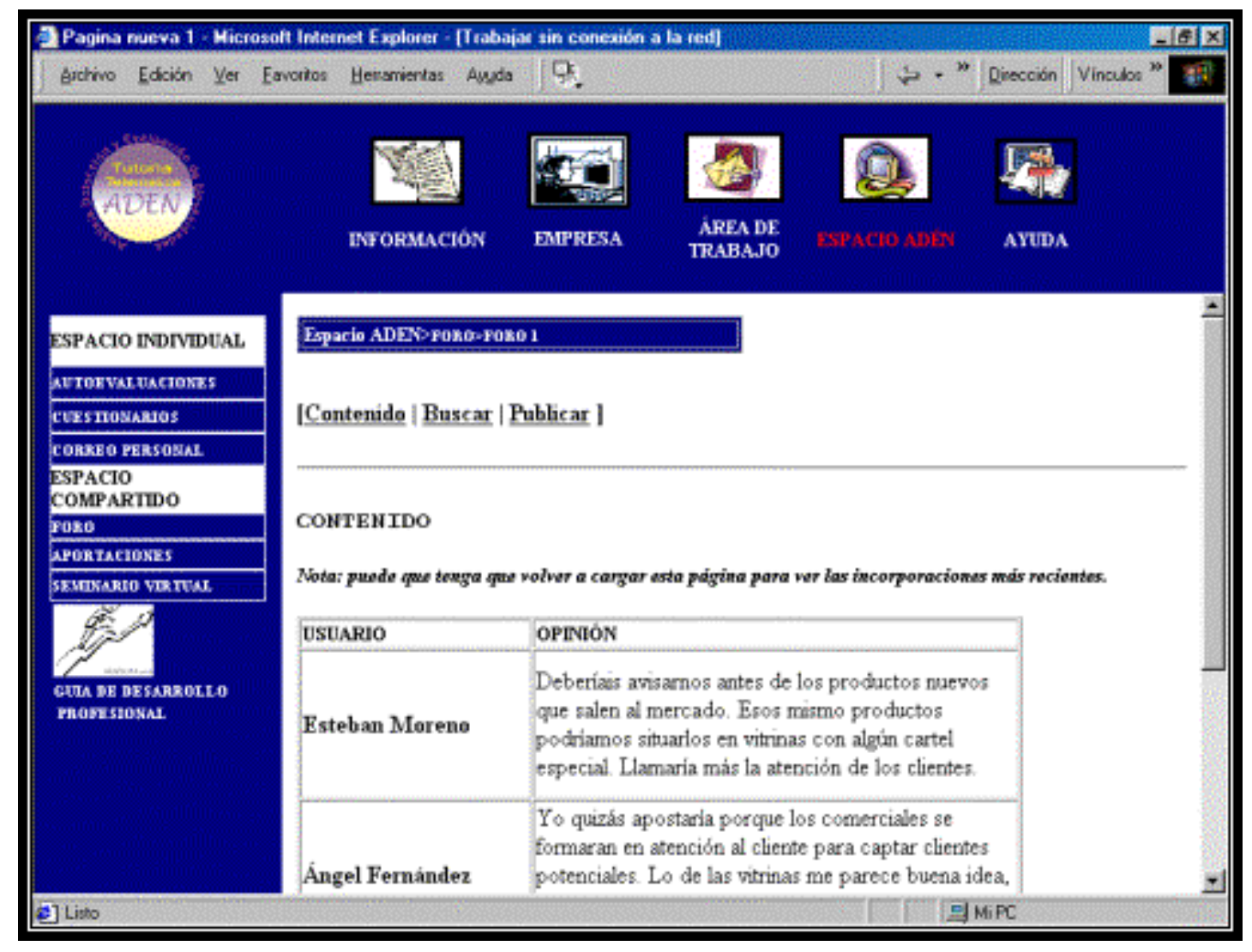

Figura 6: Unidad Espacio ADEN. Foro general.

. Foro Directivos: Es un espacio de las mismas características que el anterior, pero con la particularidad de ser un espacio abierto sólo a la participación de directivos del mismo sector (Usuarios 2). En este espacio se compartirán conocimientos sobre distintas áreas del sector e incluso se podrán fijar, en caso de acuerdo, acciones de formación agrupadas.

. Aportaciones: Espacio de aportaciones de información estructurada al grupo de tutorizados y proveniente del mismo: artículos, información de interés general, etc. Este espacio es de participación múltiple donde los tutorizados aporten documentos, información, conocimiento a los demás miembros del grupo.

. Seminario Virtual: Este espacio es un enlace al Seminario Virtual desarrollado por un grupo de investigadores del Laboratorio de Investigaciones Multimedia del IUCE de Salamanca. El fin que perseguimos al enlazar este seminario es proporcionar un espacio de debate compartido y trabajo en colaboración, donde el mediador será el tutor, sin trastocar la finalidad para la que se creó el mismo seminario.

\section{Área Ayuda:}


Es una unidad, como su nombre indica, de ayuda al usuario, que proporciona:

- Mapa de navegación: se propone el mapa general de navegación de la web para orientar al usuario y evitar pérdida o desorientación en la navegación.

- Uso de la web: En esta unidad se proponen las principales funciones de los botones de interacción, así como la filosofía para el buen uso de la tutoría (eficacia y calidad).

- Sobre tutor A.D.E.N: Ofrece información adicional sobre la tutoría A.D.E.N., autores, requisitos del sistema, resolución recomendada, navegadores, etc.

\subsection{El rol del tutor presencial}

El tutor presencial que va a realizar las tareas propias de gestión de la Tutoría Telemática A.D.E.N., no debe olvidar las funciones propias de tutor en la empresa, asentándose sobre el fomento de las relaciones personales entre los tutorizados, de manera que se promulgue un clima de trabajo colaborativo, en que la participación y la colaboración sean los puntos sobre los que se base la Tutoría A.D.E.N. Además va a ser consultor que aclara dudas e informaciones y/o remite a personal especializado en su caso, ayuda en la resolución de problemas y en la toma de decisiones y diagnostica necesidades de formación a la vez que asesora y apoya sobre la consecución de los recursos necesarios para llegar a las metas profesionales que cada tutorizado se haya planteado. Así, sus funciones se concretan en varias acciones básicas, entre las que destacamos:

- Establecer el uso más adecuado de cada medio de comunicación, y prestar atención a la fijación de los recursos de comunicación síncrona, que se establecerán conjuntamente en el tablón de anuncios o por correo personal.

- Establecer cómo se desarrollará el proceso de diagnóstico e informar a todos los usuarios del mismo.

- Proporcionar los recursos disponibles para la creación de un espacio de trabajo colaborativo.

- Gestionar la incorporación, creación y eliminación de todas los contenidos de las diferentes unidades temáticas.

- Supervisar la realización de los cuestionarios y confeccionar nuevos de cara a recoger información para la detección de necesidades formativas.

- Organizar un plan de desarrollo profesional con cada usuario.

- Atender regularmente el correo que sirve para gestionar los asuntos de índole privada.

- Asesorar y asistir personalmente al usuario que lo requiera.

- Animar y supervisar especialmente el uso de los foros que se haya decidido, entre todos, crear.

- Animar a la presentación de propuestas y trabajos propios, para el enriquecimiento de todos los usuarios.

- Informar periódicamente, mediante el tablón de anuncios, de los pasos dados en el proceso de diagnóstico.

Para realizar estas tareas deberá seguir un esquema de tutorización colaborativa, en la que será el responsable de organizar las tutorías, seguir los foros de discusión, contestar las dudas y facilitar los recursos que puedan favorecer a los tutorizados. Además debe promover la toma de iniciativa, la motivación y el fomento de la interrelación entre los participantes de esta tutoría, aportando su experiencia en el proceso de creación de este espacio común donde se compartan esos objetivos y 
recursos comunes, siempre respetando el nivel de autonomía propio de las características de las personas que participan en la tutoría.

Definimos así el rol del tutor presencial y gestor de esta tutoría, pero será propio la evaluación, en cada PYME y según como se establezca el sistema de tutoría, analizar dichas funciones y capacitar al personal que va a ejercer este rol.

\subsection{Criterios de calidad pedagógica presentes en la Tutoría Telemática A.D.E.N.}

Centrándonos propiamente en criterios pedagógicos podemos hablar de que la Tutoría A.D.E.N. posee una estructura de carácter abierto, conformando un espacio en el que se facilita la movilidad del usuario, manteniendo poca especifidad y concreción de contenidos, dando pie a la independencia y libertad de movimientos por la web. El diseño no presenta, así, demasiados contenidos preespecificados sino que, dependiendo de la empresa, se determinarán los mismos; lo que sí presenta es una estructura común que debe ser completada en cada caso. Cada una de las unidades de información y comunicación, así como las imágenes y demás elementos están planteadas con la intencionalidad pedagógica y comunicativa, comenzando incluso desde la primera página, en la que la imagen simula la reconstrucción de un puzzle que podría asemejarse a poner un poco de orden en el desarrollo profesional de cada uno, ayudando y animando a conocer sus propias necesidades y metas.

El diseño se caracteriza igualmente por la no linealidad, no espontaneidad, estando basado en una estructura abierta e hipertextual, con una serie de recursos que apoyan el intercambio de información y conocimientos y la discusión interpersonal, esquema apropiado para que los participantes, en su construcción colaborativa, puedan representar simbólicamente ideas, conceptos y relaciones, tanto para la reflexión personal como para la negociación conjunta de significados. Hemos destacado también, anteriormente, factores como la versatilidad y la facilidad de uso y de navegación para evitar la pérdida del usuario.

\section{5. Últimas consideraciones}

Una última consideración para hacer mención a la posibilidad de aplicación real de esta tutoría, mejorando y ampliando sus funciones, incluso promoviendo una gran plataforma de formación para la PYME. En ese momento será más valiosa la interpretación pedagógica de la misma Tutoría, porque será cuando podamos estudiar globalidad de las interacciones entre el diseño, las actividades, las participaciones y el contexto en sí. En la futura aplicación y posterior análisis empírico de este espacio podremos observar cómo se negocian y se elabora ese conocimiento compartido y cómo se va construyendo esa base común (de entendimiento mutuo) como plataforma que sustentará esa construcción de nuevos conocimientos y esas interacciones colaborativas.

Las teorías socioculturales creemos que dan sustento suficiente para considerar esta Tutoría como un entorno de aprendizaje flexible, eficaz y de trabajo colaborativo, con muchas posibilidades para el mundo de la formación en las PYMEs.

NOTAS BIBLIOGRÁFICAS

ANDRÉS, M. P. (2001) Gestión de la formación en la empresa. Madrid, Pirámide

Cabero, J. (ed.) Nuevas tecnologías aplicadas a la educación. Madrid, Editorial Síntesis.

CACHEIRO, M. L. (1997) "El interfaz de navegación. Diseño pedagógico”, en GALLEGO, D. J. y ALONSO, C. M. (Eds.) Multimedia. Madrid, Ediciones UNED

CASTELLS, M. (1997) La era de la Información: La Sociedad Red. Madrid, Alianza Editorial, Vol. I CÓRDOVA, P. (Coord.) La formación en las empresas españolas. Situación, tendencias y 
expectativas, [en línea]. Resumen del estudio de la CEOE, 2001. <http://www.rrhhmagazine.com> [Última consulta: 22 Junio 2003].

CROOK, Ch. (1998) Ordenadores y aprendizaje colaborativo. Madrid, Ediciones Morata

DOMÍNGUEZ, G. Los nuevos retos de las instituciones no formales: nuevas necesidades de Formación en DOMÍNGUEZ, G. Los nuevos retos de las instituciones no formales: nuevas necesidades de formación, [en línea]. <http://www.oei.es/rifad4b.htm> [Última consulta: 22 Junio 2003].

FERNÁNDEZ-SALINERO, C. (2002) Las necesidades de formación laboral en las PYMEs. Oviedo, Septem Ediciones

GIL, P. (2001) E-Formación. Bilbao, Ediciones Deusto.

GLADSTONE, A. y OZAQUI, M. (comps.) (1994) Participación de los trabajadores en la empresa, nuevas tecnologías y programas de formación. Informes OIT. Madrid, Centro de publicaciones Ministerio de Trabajo y Seguridad Social

JIMÉNEZ, A., PIMENTEL, M. Y ECHEVERRÍA, M. (2002) España 2010: Mercado Laboral. Proyecciones e Implicaciones empresariales. Madrid, Editorial Díaz de Santos

NEWMAN, D.; GRIFFIN, P. y COLE, M. (1991) La zona de construcción de conocimiento: trabajando por un cambio cognitivo en educación. Madrid, MEC-Ediciones Morata

PINEDA, P. (coord.) Pedagogía Laboral. Barcelona, Ariel Educación

TIRADO, C., GRANGER, J. R. y NIETO, M. (1995) La PYME del siglo XXI. Madrid, Fundesco.

VIRTUAL EDUCA (2001), Actas de la Conferencia Internacional sobre Educación, Formación y Nuevas Tecnologías, Vol. II. Madrid, Ediciones UNED

[1] Herramienta on line dirigida a realizar un autoanálisis de la trayectoria profesional hasta el momento y la fijación de metas profesionales http://www.careerstorm.com/navigator/en/index.asp Debido a la volubilidad de la red Internet, esta herramienta ha sido retirada por el momento en castellano, estando disponible sólo en Inglés. Es una herramienta gratuita muy interesante, por eso aprovechamos este recurso en la Tutoría ADEN.

(C) Ediciones Universidad de Salamanca 